\title{
Investigation of the Allelopathic Effect of Matricaria chamomilla L. Parts' Aqueous Extracts on Germination and Seedling Growth of Two Moroccan Varieties of Durum Wheat
}

\author{
Amine Elbouzidi ${ }^{D},{ }^{1}$ Noureddine Bencheikh $\left(\mathbb{D},{ }^{2}\right.$ Sara Seddoqi, ${ }^{2}$ Mohamed Bouhrim $\left(\mathbb{D},{ }^{2}\right.$ \\ Youssef Bouramdane, ${ }^{3}$ and Mohamed Addi $\oplus^{1}$ \\ ${ }^{1}$ Laboratory for Agricultural Productions Improvement, Biotechnology and Environment, Faculty of Sciences, \\ University of Mohammed Premier, Oujda, Morocco \\ ${ }^{2}$ Laboratory of Bioresources Biotechnology Ethnopharmacology and Health, Department of Biology, Faculty of Sciences, \\ University Mohamed the First, Oujda, Morocco \\ ${ }^{3}$ Office of Sanitary Safety of Food Products (ONSSA), Seed and Plants Control Service, Oujda, Morocco \\ Correspondence should be addressed to Mohamed Addi; m.addi@ump.ac.ma
}

Received 9 April 2021; Revised 29 May 2021; Accepted 4 June 2021; Published 16 June 2021

Academic Editor: Cristina Patan

Copyright (C) 2021 Amine Elbouzidi et al. This is an open access article distributed under the Creative Commons Attribution License, which permits unrestricted use, distribution, and reproduction in any medium, provided the original work is properly cited.

\begin{abstract}
The phenomenon of allelopathy has been known for more than 2000 years. This phenomenon consists of the chemical interference of plant species (or other organisms), by enhancing, or inhibiting, the germination, seedling growth, or development of other plant species (or other organisms). This paper aimed to investigate the allelopathic potential of the aqueous extract of different parts of Matricaria chamomilla L. on germination parameters (radicle, coleoptile length, and dry weight) of two Moroccan varieties of durum wheat. Chamomile extracts from leaves, roots, or flowers at concentrations of 50 and $100 \mathrm{~g} \cdot \mathrm{L}^{-1}$ were prepared and applied to wheat durum seeds. The control group was given distilled water. In both studied varieties of durum wheat, only flowers' aqueous extracts showed a significant positive allelopathic effect by increasing the studied parameters, while leaves and roots from chamomile showed an inhibiting potential on germination and seedling growth in varieties riyad and kanakis.
\end{abstract}

\section{Introduction}

Durum wheat (Triticum turgidum L. subsp. durum (Desf.) Husn.) is an allotetraploid ( $2 n=4 x=28$ chromosomes; genome formula MMUU), resulting from the intergeneric hybridization and polyploidization of two species of the Poaceae family, Triticum urartu and Aegilops speltoides [1]. Durum wheat is considered as a minor cereal crop, with about $5 \%$ of wheat crop production, which, in 2019, has surmounted 760 million tons [2]. In Morocco, late rainfall delayed planting followed by adverse weather conditions, particularly elevated temperatures from January to March, affected crop growth, and reduced production (4.02MT in 2020), and recent data collected from the FAO outline a decline in wheat production (in which durum) of $25.4 \%$ compared to 2019 and almost 50\% compared to the 5-year average [3]. Weeds are responsible for heavy yield losses in wheat because of their competition for water, nutrients, and light, as well as for their phytochemicals interference with wheat, posing a significant biological constraint to crop productivity [4]. The interactions between plants is called "Allelopathy," which has been defined as the direct or indirect, detrimental or beneficial effects of one plant on another through the production of chemical compounds that escape into the environment, through leaching, root exudation, volatilization, and decomposition of plant residues [5]; as a result, it plays a significant role in plant dominance, succession, plant populations and climax vegetation development, and crop production [6, 7]. The substances involved in this biological phenomenon are plant 
allelochemicals [8]. The stimulating allelopathic effects of any plant on the other plant could be used to produce "green growth promoters" [9], as well as using them for their potential uses in agriculture as weed control agents "bioherbicides" [10].

Allelopathy is indeed a recent branch of plant biology, and there is very little work carried out on the allelopathic potential of Moroccan flora on crops.

Matricaria chamomilla L., also known as German Camomile, is a flowering plant that belongs to the Asteraceae family, native to Europe and Asia and also found in Australia and North America, North Africa, and New Zeeland [11]. In crop rotation, volunteer camomile seeds are a major issue. Following harvest, a lot of grain remains on the field and germinates throughout the subsequent cultivation. Therefore, it is crucial to have a following crop tolerant to allelochemicals produced by camomile. Throughout this short communication, we investigate the allelopathic effect of M. chamomilla aqueous extracts of various parts on seed germination and seedling growth of two Moroccan durum wheat varieties, namely, kanakis and riyad.

\section{Materials and Methods}

2.1. General Procedure. The experiment was carried out at the Department of Biology, Faculty of Sciences, Mohammed First University of Oujda, from September to November 2020. The two certified durum wheat (Triticum turgidum L. subsp. durum (Desf.) Husn.) varieties used in this study, kanakis and riyad, were given by the ONSSA (Office of Sanitary Safety of Food Products).

2.2. Plant Harvest. Matricaria chamomilla L. plants were collected from fields $\left(34^{\circ} 43^{\prime} 57.1^{\prime \prime} \mathrm{N} 1^{\circ} 56^{\prime} 57.0^{\prime \prime} \mathrm{W}, 539 \mathrm{~m}\right.$ altitude) in Oujda-Angad Province, Oujda City, Morocco, and have been taxonomically identified and registered under the voucher specimen number HUMPOM***.

2.3. Preparation of the Aqueous Extracts. In order to obtain the aqueous extracts of different Chamomile parts, plants were separated into flowers, leaves, and roots and then dried at room temperature for 5 days. The dried parts were grounded, decoct in distilled water, and filtrated, and the filtrates were placed in the oven at $40^{\circ} \mathrm{C}$ for $24 \mathrm{~h}$ to evaporate water and obtain the extracts in a powder form as reported in $[12,13]$, with slight modifications. Aqueous extracts of different concentrations were prepared as follow: 50 and $100 \mathrm{~g}$ of dried powder of each part were soaked for $24 \mathrm{~h}$ in $1 \mathrm{~L}$ of sterile distilled water at room temperature. Aqueous extracts were stored at $4^{\circ} \mathrm{C}$.

\subsection{Bioassays in the Laboratory}

2.4.1. Sterilisation of Test Plants (Seeds). Experiments were executed following the internationally accepted guide for seed testing [14]. Four hundred and twenty seeds of each durum wheat cultivar were surface sterilized in 1:20 dilution of commercial hypochlorite bleach for $10 \mathrm{~min}$ and rinsed with distilled water several times, and then, the seeds were allowed to soak for $2 \mathrm{~h}$ on moistened paper towels.

2.4.2. Seed Germination and Seedling Growth Bioassays. Sterile filter papers (Whatman No. 1) containing seeds (10 per plate) were placed in each sterilized $9 \mathrm{~cm}$ Petri plates. $10 \mathrm{~mL}$ of each extract solution mentioned above was added. Sterile distilled water was used as a control, and each treatment has been replicated 3 times. Plants were grown at constant temperature $\left(25 \pm 1^{\circ} \mathrm{C}\right)$ with a $16 \mathrm{~h} / 8 \mathrm{~h}$ (light/dark) cycle for 7 days. During these tests, no fungal contaminations have been detected. Towards the end of the testing period, the germination and seedling growth parameters, in particular radicle and coleoptile lengths with ImageJ software and seedling dry weight with a precision balance, were recorded and germination indices were calculated, namely, Mean Germination Time (MGT), T50, seedling vigour index, and the allelopathic index (AI).

2.5. Data Analysis. The following indexes were evaluated:

(i) Percentage of final germination (G\%), calculated as in (1), where $N$ is the sum of seeds and $N_{i}$ is the number of germinated seeds at the end of the experiment duration:

$$
\operatorname{GR}(\%)=\frac{\mathbf{N}_{\mathbf{i}}}{\mathbf{N}} \times 100
$$

$\mathbf{N}_{\mathbf{i}}$ : germinated seeds per day and $\mathrm{N}$ : counting day

(ii) Mean Germination Time (MGT), calculated using equation (2), as described by [15]:

$$
\text { MGT }=\frac{\sum_{\mathbf{i}=1}^{\mathbf{k}} \mathbf{n}_{\mathbf{i}} \mathbf{t}_{\mathbf{i}}}{\sum_{\mathbf{i}=1}^{\mathbf{k}} \mathbf{n}_{\mathbf{i}}},
$$

where $\mathbf{n}_{\mathbf{i}}$ and $\mathbf{t}_{\mathbf{i}}$ are consecutively the numbers of newly germinated seeds in the last time and the time from the beginning of the experiment to the last observation; $\mathbf{k}=$ last time of germination.

(iii) $\mathrm{T}_{50}$ or time required for the germination of $50 \%$ of seeds, following the formula in [16] modified in [17], computed as follows:

$$
\mathbf{T}_{50}=\frac{\left[\left\{(\mathbf{N} / 2)-\mathbf{n}_{\mathbf{i}}\right\}\left(\mathbf{t}_{\mathbf{i}}-\mathbf{t}_{\mathbf{j}}\right)\right]}{\left(\mathbf{n}_{\mathbf{i}}-\mathbf{n}_{\mathbf{j}}\right)},
$$

where $\mathbf{N}$ is the final emergence number and $\mathbf{n}_{\mathbf{i}}$ and $\mathbf{n}_{\mathbf{j}}$ are the sum number of seeds germinated by neighbouring counts at $\mathbf{t}_{\mathbf{i}}$ and $\mathbf{t}_{\mathbf{j}}$ times, respectively, when $\mathbf{n}_{\mathbf{i}}<\mathbf{N} / 2<\mathbf{n}_{\mathbf{j}}$.

(iv) We defined an allelopathic index (AI) to reflect the intensity of the allelopathic effect. AI was calculated according to the work of Luo et al. [18], as follows:

$$
\mathbf{A I}(\%)=\left[\frac{(\mathbf{G i}-\mathbf{G c})}{\mathbf{G c}}\right] \times 100,
$$


where $\mathbf{G i}$ is the germination rate in extract concentration $\mathbf{i}$ and $\mathbf{G c}$ is the germination rate of the control (given sterile distilled water). An $\mathbf{A I}<0$ reflects a negative allelopathic effect of chamomile extracts on seed germination, and an $\mathbf{A I}>0$ value indicates a promoting effect on the germination, while the absolute value of $\mathbf{A I}$ indicated the allelopathic intensity.

2.6. Statistical Analysis. All the experiments were performed in a completely randomized design. The data were subjected to one-way analysis of variance and were presented as mean \pm SEM (Standard Error of the Mean) and separated at $p<0.05, p<0.01$, and $p<0.001$ applying Dunnett's test. The statistical analysis was conducted using GraphPad Prism version 5.01 software.

\section{Results and Discussion}

The aqueous extracts of flowers, leaves, and roots of M. chamomilla have been evaluated at 50 and $100 \mathrm{~g} \cdot \mathrm{L}^{-1}$, for their allelopathic potential on germination (Table 1) and seedling growth parameters (Table 2) of two varieties of durum wheat in Morocco. The allelopathic effects of M. chamomilla on germination percentage, mean germination time (MGT), time required for the germination of $50 \%$ of seeds $\left(\mathrm{T}_{50}\right)$, and seed vigour index (SVI) are shown in Table 1.

For the kanakis variety, germination of the control $\left(0 \mathrm{~g} \cdot \mathrm{L}^{-1}\right)$ was $95 \%$. Application of flowers' extracts had a slight stimulatory effect but it did not show any significant difference, while the application of leaves' aqueous extract at a dose of $100 \mathrm{~g} \cdot \mathrm{L}^{-1}$ and roots at both doses had an inhibitory effect on germination with 65,70 , and $48.34 \%$, respectively. For the riyad variety, same effects were noticed (except for leaves $50 \mathrm{~g} \cdot \mathrm{L}^{-1}$, a significant inhibitory effect was also observed). The effect of chamomile parts' aqueous extracts on germination was more pronounced in riyad than that seen in the kanakis variety (Table 1). Germination reduction is the most apparent allelopathic action in allelopathy bioassays $[19,20]$.

In both kanakis and riyad varieties of durum wheat, a marked effect is, thus, noted regarding the mean germination time and time required for the germination of $50 \%$ of seeds, the highest detrimental effect was observed in the $100 \mathrm{~g} \cdot \mathrm{L}^{-1}$ flowers group with $100 \%$, and the lowest one was recorded in the $100 \mathrm{~g} \cdot \mathrm{L}^{-1}$ roots group $(48.3 \%)$.

From these results, it was found that root extracts prolonged the germination time of both varieties.

The data on the allelopathic effect of different parts of $M$. chamomilla on germination, radicle, and coleoptile length of durum wheat varieties (kanakis and riyad) are expressed in Table 2.

Seed germination has been impaired by the inhibitory influence of extracts from fresh $M$. chamomilla plant leaves and roots solutions, while flower solutions did not affect wheat germination $(p>0.05)$. The intensity of inhibition improved with the concentration of the extract. Leaf and root extracts (at both concentrations, 50 and $100 \mathrm{~g} \cdot \mathrm{L}^{-1}$ ) have substantially decreased germination compared with the control (distilled water) in kanakis and riyad varieties. These results are supported by those of Chung and Miller, 1995 [21].

For the development of coleoptiles, it turned out that all the extracts from leaves, flowers, and roots have a significant effect on the kanakis variety $(p<0.001)$, while for the riyad variety, no significant difference in coleoptile lengths was noticed for flowers treated seeds in both concentrations. Radicle length was affected similarly as coleoptile length, in kanakis variety as well as in riyad variety with a slight improvement in the kanakis variety at the highest concentration $\left(100 \mathrm{~g} \cdot \mathrm{L}^{-1}\right)$ of flowers. The different parts of M. chamomilla and their extracts had a significant impact on seedling dry weight in the studied durum wheat varieties. The highest seedling dry weights $61.84 \mathrm{mg}$ and $67.35 \mathrm{mg}$ were recorded when using $\left(100 \mathrm{~g} \cdot \mathrm{L}^{-1}\right)$ of flowers extract, and the lowest $29.18 \mathrm{mg}$ and $28.14 \mathrm{mg}$ were remarked when using the highest concentration of roots $\left(100 \mathrm{~g} \cdot \mathrm{L}^{-1}\right)$ in the kanakis and riyad variety, respectively.

The allelopathic index was calculated to unveil the unknown allelopathic effects of treatments versus control (treated only with distilled water) [22]. Figure 1 represents the allelopathic index of kanakis (Figure 1(a)) and riyad (Figure 1(b)) varieties.

For kanakis (Figure 1(a)), it was found that flowers' aqueous extract at 50 and $100 \mathrm{~g} \cdot \mathrm{L}^{-1}$ have a positive allelopathic index with 17.74 and $22.46 \%$, respectively. A similar effect was noticed for leaves at $50 \mathrm{~g} \cdot \mathrm{L}^{-1}$, while for the second dose $\left(100 \mathrm{~g} \cdot \mathrm{L}^{-1}\right)$, no significant change was noted versus control. Roots were the most detrimental at both doses with a negative allelopathic index of -17.48 and $-24.92 \%$, respectively, with the doses $50 \mathrm{~g} \cdot \mathrm{L}^{-1}$ and $100 \mathrm{~g} \cdot \mathrm{L}^{-1}$.

It was noticed that flowers (at the tested doses) did not show any inhibitory or promoting effect on the riyad variety (Figure 1(b)). For leaves and unlike the kanakis variety, they exhibit a negative allelopathic effect for $100 \mathrm{~g} \cdot \mathrm{L}^{-1}$ while the $50 \mathrm{~g} \cdot \mathrm{L}^{-1}$ dose did not affect significantly the allelopathic index $(p>0.05)$. Similarly, to kanakis, the effect of roots from $M$. chamomilla was well pronounced in the riyad variety, with $-31.30 \%$ for the dose $50 \mathrm{~g} \cdot \mathrm{L}^{-1}$ and $-36.00 \%$ for $100 \mathrm{~g} \cdot \mathrm{L}^{-1}$.

These results suggest that the riyad variety is more sensitive to the interaction with $M$. chamomilla leaves and roots, than the kanakis variety.

Root extract was the most inhibitory at all extracts, while the extract of leaves was the least inhibitory. The results found in this study are inconsistent with those in [20], where it was reported that the most inhibitory effect of allelopathic plants was produced by root extracts. Our findings confirmed chamomile's allelopathic effect, demonstrating that aqueous extracts from the leaves and roots of $M$. chamomilla had a significant inhibitory effect on durum wheat germination and seedling growth. A study conducted by Reichling et al. revealed that root oil contains numerous compounds such as linalool, geraniol, $\beta$-elemene, (E)- $\beta$-farnesene, $\alpha$-farnesene, spathulenol, $\tau$-cadinol, $\tau$-muurolol, $\beta$-caryophyllene, and chamomillol [23]. In addition, several phytochemical studies on the aerial parts revealed a huge 
TABLE 1: Effects of Chamomile aqueous extracts on germination percentage (\%), mean.

\begin{tabular}{|c|c|c|c|c|c|c|}
\hline & Chamomile parts & E.C $\left(g \cdot L^{-1}\right)$ & Germination percentage (\%) & MGT (days) & $\mathrm{T}_{50}$ (days) & SVI (seed vigour index) \\
\hline \multirow{7}{*}{ Var. kanakis } & \multirow{3}{*}{ Flowers } & 0 & $95.00 \pm 1.67$ & $4.26 \pm 0.01$ & $3.70 \pm 0.20$ & $2981 \pm 64.93$ \\
\hline & & 50 & $96.67 \pm 0.00 \mathrm{~ns}$ & $3.62 \pm 0.0^{* *}$ & $3.13 \pm 0.05 \mathrm{~ns}$ & $3469 \pm 52.67 \mathbf{n s}$ \\
\hline & & 100 & $100.0 \pm 0.00 \mathrm{~ns}$ & $3.48 \pm 0.08^{* *}$ & $3.07 \pm 0.14 \mathbf{n s}$ & $4110 \pm 32.13^{*}$ \\
\hline & \multirow{2}{*}{ Leaves } & 50 & $81.67 \pm 1.66 \mathrm{~ns}$ & $3.75 \pm 0.03^{*}$ & $3.13 \pm 0.20 \mathrm{~ns}$ & $2210 \pm 205.6 \mathbf{n s}$ \\
\hline & & 100 & $65.00 \pm 8.33^{* *}$ & $4.34 \pm 0.12 \mathbf{~ n s}$ & $3.84 \pm 0.04 \mathbf{n s}$ & $1635 \pm 467.9^{* *}$ \\
\hline & \multirow{2}{*}{ Roots } & 50 & $70.00 \pm 3.33^{* *}$ & $5.16 \pm 0.01^{* * *}$ & $4.92 \pm 0.25 \mathrm{~ns}$ & $1210 \pm 149.1^{* *}$ \\
\hline & & 100 & $48.34 \pm 1.66^{* * *}$ & $5.68 \pm 0.18^{* * *}$ & $5.65 \pm 0.55^{* *}$ & $523.1 \pm 8.86^{* * *}$ \\
\hline \multirow{7}{*}{ Var. riyad } & \multirow{3}{*}{ Flowers } & 0 & $98.34 \pm 1.66$ & $3.62 \pm 0.17$ & $2.97 \pm 0.28$ & $3715 \pm 39.60$ \\
\hline & & 50 & $90.00 \pm 3.33 \mathrm{~ns}$ & $3.50 \pm 0.11 \mathrm{~ns}$ & $2.98 \pm 0.10 \mathrm{~ns}$ & $3341 \pm 97.96 \mathbf{n s}$ \\
\hline & & 100 & $93.34 \pm 3.33 \mathrm{~ns}$ & $3.07 \pm 0.03 \mathrm{~ns}$ & $2.51 \pm 0.23 \mathrm{~ns}$ & $3715 \pm 192.4 \mathrm{~ns}$ \\
\hline & \multirow{2}{*}{ Leaves } & 50 & $63.33 \pm 10.0^{* *}$ & $3.98 \pm 0.10 \mathrm{~ns}$ & $3.23 \pm 0.09 \mathrm{~ns}$ & $1752 \pm 44.4^{* *}$ \\
\hline & & 100 & $53.34 \pm 3.33^{* *}$ & $4.76 \pm 0.23^{* *}$ & $4.44 \pm 0.31^{* *}$ & $1092 \pm 184.0^{* * *}$ \\
\hline & \multirow{2}{*}{ Roots } & 50 & $55.00 \pm 1.67^{* *}$ & $5.27 \pm 0.16^{* * *}$ & $5.00 \pm 0.17^{* * *}$ & $1094 \pm 25.04^{* * *}$ \\
\hline & & 100 & $30.00 \pm 3.33^{* * *}$ & $5.67 \pm 0.07^{* * *}$ & $5.53 \pm 0.13^{* * *}$ & $371.4 \pm 80.70^{* * *}$ \\
\hline
\end{tabular}

Note: data are expressed as mean \pm SEM, $n=30$, ns: not significant; ${ }^{*} p<0.05 ;{ }^{* *} p<0.01 ;{ }^{* * *} p<0.001$. E.C: extract concentration germination time (MGT), T50, and seed vigour index (SVI) of the studied varieties.

TABLE 2: Effects of chamomile aqueous extracts on seedling growth of the durum wheat kanakis and riyad variety.

\begin{tabular}{|c|c|c|c|c|c|}
\hline & Camomile parts & E.C $\left(g \cdot L^{-1}\right)$ & Coleoptile length $(\mathrm{mm})$ & Radicle length $(\mathrm{mm})$ & Dry weight per seedling $(\mathrm{mg})$ \\
\hline \multirow{7}{*}{ Var. kanakis } & \multirow{3}{*}{ Flowers } & 0 & $31.65 \pm 0.71$ & $31.38 \pm 0.65$ & $53.94 \pm 2.06$ \\
\hline & & 50 & $38.40 \pm 0.66^{* * *}$ & $35.89 \pm 0.86^{* *}$ & $52.24 \pm 2.12 \mathrm{~ns}$ \\
\hline & & 100 & $42.45 \pm 0.87^{* * *}$ & $41.10 \pm 0.98^{* * *}$ & $61.84 \pm 1.16^{* *}$ \\
\hline & \multirow{2}{*}{ Leaves } & 50 & $24.30 \pm 1.22^{* * *}$ & $27.06 \pm 1.29^{*}$ & $47.49 \pm 2.19$ ns \\
\hline & & 100 & $22.32 \pm 1.33^{* * *}$ & $25.18 \pm 1.46^{* * *}$ & $42.74 \pm 1.60^{* * *}$ \\
\hline & \multirow{2}{*}{ Roots } & 50 & $20.82 \pm 1.10^{* * *}$ & $17.28 \pm 1.13^{* * *}$ & $34.25 \pm 1.90^{* * *}$ \\
\hline & & 100 & $14.97 \pm 0.94^{* * *}$ & $10.83 \pm 0.99^{* * *}$ & $29.18 \pm 2.10^{* * *}$ \\
\hline \multirow{7}{*}{ Var. riyad } & \multirow{3}{*}{ Flowers } & 0 & $37.78 \pm 0.71$ & $37.63 \pm 1.06$ & $61.85 \pm 0.66$ \\
\hline & & 50 & $37.14 \pm 0.29 \mathbf{n s}$ & $37.48 \pm 1.12$ ns & $63.71 \pm 0.81 \mathbf{n s}$ \\
\hline & & 100 & $39.79 \pm 0.64 \mathrm{~ns}$ & $41.80 \pm 0.95^{*}$ & $67.35 \pm 0.21^{*}$ \\
\hline & \multirow{2}{*}{ Leaves } & 50 & $27.23 \pm 2.71^{* *}$ & $32.54 \pm 0.74^{* *}$ & $57.34 \pm 0.07^{*}$ \\
\hline & & 100 & $20.34 \pm 2.17^{* * *}$ & $29.14 \pm 0.89^{* * *}$ & $55.59 \pm 0.97^{* *}$ \\
\hline & \multirow{2}{*}{ Roots } & 50 & $19.93 \pm 1.05^{* * *}$ & $17.28 \pm 1.13^{* * *}$ & $44.11 \pm 1.45^{* * *}$ \\
\hline & & 100 & $12.23 \pm 1.33^{* * *}$ & $10.83 \pm 0.99^{* * *}$ & $28.14 \pm 1.51^{* * *}$ \\
\hline
\end{tabular}

Note: data are expressed as mean $\pm \operatorname{SEM}, n=30$, ns: not significant; ${ }^{*} p<0.05 ;{ }^{* *} p<0.01 ;{ }^{* * *} p<0.001$. E.C: extract concentration.

diversity in secondary compounds, and about 120 principals such as polyphenols and flavonoids were identified [24]. In the scientific literature, these compounds were largely known for their allelopathic effect [25-27]. The noticed inhibition exerted by chamomile's roots may be due to the difference in their active principals, as they differ considerably from the aerial parts [23]. The probable mechanisms of action of root extract are many, root aqueous extract may contain phytotoxic compounds, and the mechanisms possible of this negative allelopathic interference are the inhibition of the synthesis and/or activities of gibberellic acid and other endogenous hormones [28, 29], cell division and elongation [29], protein synthesis [30], and respiration [31]. The kanakis variety was more susceptible to autotoxic allelochemicals than the riyad variety. Previous research has found that the allelopathic activity is dependent on the concentration of the extract, the target organisms, and the plant tissues from which the chemicals are extracted [19, 32-34].

Chamomile leaves and roots aqueous extracts adversely affect seed germination and seedling growth of two varieties of durum wheat that are commonly intercropped with chamomile. The phytotoxicity of chamomile, according to this study, may be classified in the following order of decreasing inhibition: roots $>$ leaves $>$ flowers. In conclusion, Matricaria chamomilla L. must be considered as an allelopathic species posing risk in a rotation or intercropping or mixed cropping systems. 


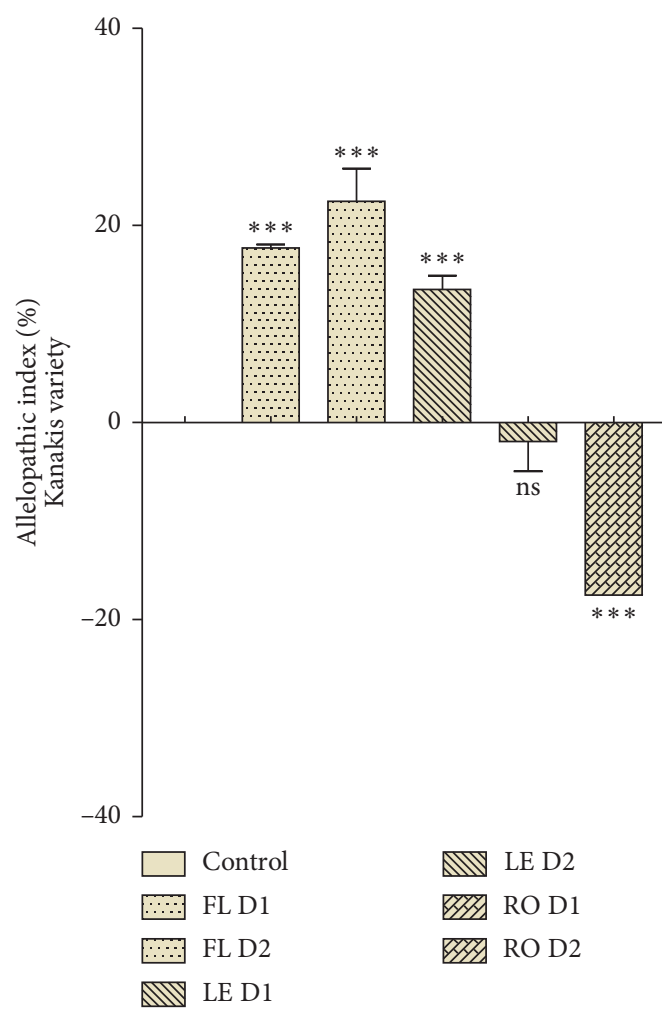

(a)

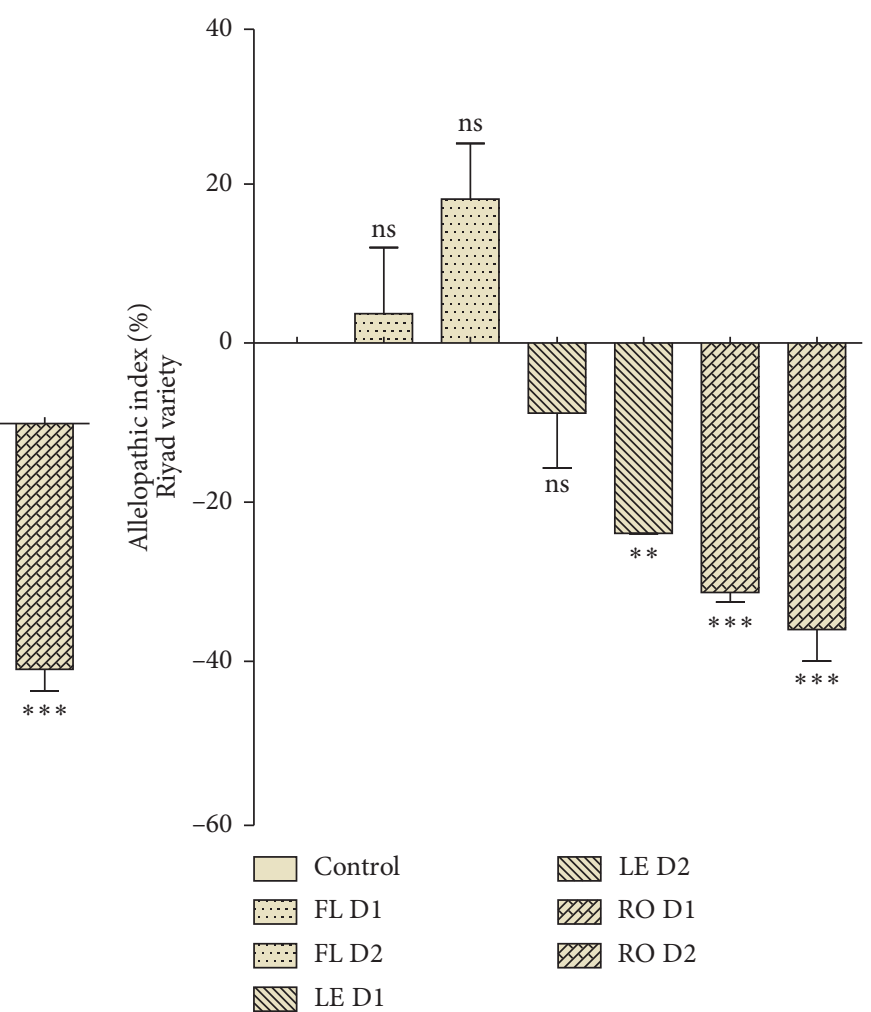

(b)

FIGURE 1: Impact of chamomile's different parts on the allelopathic index (\%) of the kanakis variety (a) and riyad variety of durum wheat (b). Data are expressed as mean $\pm \mathrm{SEM}, n=30$, ns: not significant; ${ }^{* *} p<0.01{ }^{* * *} p<0.001$. FL: flowers, LE: leaves, RO: roots, and D1 and D2: $50 \mathrm{~g} \cdot \mathrm{L}^{-1}$ and $100 \mathrm{~g} \cdot \mathrm{L}^{-1}$, respectively.

\section{Conclusions}

In this investigation, we were able to observe that the behaviour of durum wheat changed according to chamomile's different parts in a dose-dependent manner. This study investigates for the first time the effect of M. chamomilla on germination and seedling growth of durum wheat in Morocco. Further research should be carried out to isolate the allelopathic compounds and to reveal the physiological and biochemical aspects behind this remarked interference.

\section{Data Availability}

The data used to support the findings of this study are available from the corresponding author upon request.

\section{Conflicts of Interest}

The authors declare no conflicts of interest regarding the publication of this paper.

\section{Acknowledgments}

The authors thank the service of seeds and plants protection in Oujda, Morocco, for the seeds of durum wheat used in this study.

\section{References}

[1] M. Kovárová, P. Suchánková, J. Ćíhalíková et al., "Chromosome sorting in tetraploid wheat and its potential for genome analysis," Genetics, vol. 170, no. 2, pp. 823-829, 2005.

[2] Faostat, "Crops," 2020, http://www.fao.org/faostat/en/\#data/ $\mathrm{QC} /$.

[3] FAO, Crop Prospects And Food Situation Quarterly Global Report No. 2, Food and Agriculture Organization, Washington, DC, USA, 2020.

[4] S.-Z. Zhang, Y.-H. Li, C.-H. Kong, and X.-H. Xu, "Interference of allelopathic wheat with different weeds," Pest Management Science, vol. 72, no. 1, pp. 172-178, 2016.

[5] M. J. Reigosa, A. Sánchez-Moreiras, and L. González, "Ecophysiological approach in allelopathy," Critical Reviews in Plant Sciences, vol. 18, no. 5, pp. 577-608, 1999.

[6] E. L. RICE, "Introduction," in Allelopathy, E. L. Rice, Ed., pp. 1-7, Academic Press, San Diego, CA, USA, 2nd edition, 1984.

[7] S. J. H. Rizvi, H. Haque, V. K. Singh, and V. Rizvi, "A discipline called allelopathy," in Allelopathy: Basic and Applied Aspects, S. J. H. Rizvi and V. Rizvi, Eds., Springer, Dordrecht, Netherlands, pp. 1-10, 1992.

[8] C. Das, A. Dey, and A. Bandyopadhyay, "Allelochemicals: an emerging tool for weed management," in Evidence Based Validation of Traditional Medicines: A Comprehensive Approach, S. C. Mandal, R. Chakraborty, and S. Sen, Eds., Springer, Singapore, pp. 249-259, 2021. 
[9] P. Oudhia, B. S. Joshi, and V. K. Kosta, "The possibilities of preparing homeopathic drugs from the obnoxious weed of Chhattisgarh," Bhartiya Krishi Anusandhan Patrika, vol. 13, pp. 53-57, 1998.

[10] F. A. Macías, J. M. Molinillo, R. M. Varela, and J. C. Galindo, "Allelopathy-a natural alternative for weed control," Pest Management Science, vol. 63, no. 4, pp. 327-348, 2007.

[11] G. W. Ivens, "Weeds OF note-stinking mayweed," New Zealand Journal of Agricultural, vol. 138, no. 3, p. 21, 1979.

[12] N. Chopra, G. Tewari, L. M. Tewari, B. Upreti, and N. Pandey, "Allelopathic effect of Echinochloa colona L. And Cyperus iria L. Weed extracts on the seed germination and seedling growth of rice and soyabean," Advances in Agriculture, vol. 2017, Article ID 5748524, 5 pages, 2017.

[13] S. Siddiqui, S. Bhardwaj, S. S. Khan, and M. K. Meghvanshi, "Allelopathic effect of different concentration of water extract of Prosopsis juliflora leaf on seed germination and radicle length of wheat (Triticum aestivum Var-Lok-1)," American Journal of Scientific Research, vol. 4, no. 2, pp. 81-84, 2009.

[14] International Seed Testing Association, International Rules for Seed Testing, International Seed Testing Association, Bassersdorf, Switzerland, 2021.

[15] M. A. Ranal, D. G. D. Santana, W. R. Ferreira, and C. MendesRodrigues, "Calculating germination measurements and organizing spreadsheets," Revista Brasileira de Botânica, vol. 32, no. 4, pp. 849-855, 2009.

[16] P. Coolbear, A. Francis, and D. Grierson, "The effect of low temperature pre-sowing treatment on the germination performance and membrane integrity of artificially aged tomato seeds," Journal of Experimental Botany, vol. 35, no. 11, pp. 1609-1617, 1984.

[17] M. Farooq, S. M. A. Basra, B. A. Saleem, M. Nafees, and S. A. Chishti, "Enhancement of tomato seed germination and seedling vigor by osmopriming," Pakistan Journal of Agricultural Sciences, vol. 42, pp. 3-4, 2005.

[18] Y. Luo, X. Zhao, Y. Li, and T. Wang, "Effects of foliage litter of a pioneer shrub (Artemisia halodendron) on germination from the soil seedbank in a semi-arid sandy grassland in China," Journal of Plant Research, vol. 130, no. 6, pp. 1013-1021, 2017.

[19] A.-P. Wu, H. Yu, S.-Q. Gao et al., "Differential belowground allelopathic effects of leaf and root of Mikania micrantha," Trees, vol. 23, no. 1, pp. 11-17, 2009.

[20] A. Ballester, A. M. Vieitez, and E. Vieitez, "The allelopathic potential of erica australis L. And E. Arborea L," Botanical Gazette, vol. 140, no. 4, pp. 433-436, 1979.

[21] I. M. Chung and D. A. Miller, "Effect of alfalfa plant and soil extracts on germination and growth of alfalfa," Agronomy Journal, vol. 87, no. 4, pp. 762-767, 1995.

[22] M. H. Far and A. Bagherzadeh, "Assessing allelopathic index for estimating allelopathic potential of Ajowan extracts," Journal of Crop Science and Biotechnology, vol. 21, no. 2, pp. 165-172, 2018.

[23] J. Reichling, R. Beiderbeck, and H. Becker, "Comparative studies on secondary products from tumors, flowers, herb and roots of Matricaria chamomilla L," Planta Medica, vol. 36, 1979.

[24] J. A. Pino, F. Bayat, R. Marbot, and J. Aguero, "Essential oil of Chamomile Chamomilla recutita (L.) rausch. From Iran," Journal of Essential Oil Research, vol. 14, no. 6, pp. 407-408, 2002.

[25] L. A. Weston and U. Mathesius, "Flavonoids: their structure, biosynthesis and role in the rhizosphere, including allelopathy," Journal of Chemical Ecology, vol. 39, no. 2, pp. 283-297, 2013.

[26] J. John and S. Sarada, "Role of phenolics in allelopathic interactions," Allelopathy Journal, vol. 29, no. 2, 2012.

[27] E. L. Rice, "Allelopathy-An update," The Botanical Review, vol. 45, no. 1, pp. 15-109, 1979.

[28] M. Olofsdotter, "Rice-A step toward use of allelopathy," Agronomy Journal, vol. 93, no. 1, pp. 3-8, 2001.

[29] Z.-H. Li, Q. Wang, X. Ruan, C.-D. Pan, and D.-A. Jiang, "Phenolics and plant allelopathy," Molecules, vol. 15, no. 12, pp. 8933-8952, 2010.

[30] H. Q. Hua and W. X. Lin, "Studies on allelopathic physio bio chemical characteristics of rice," Chinese Journal of Eco-Agriculture, vol. 9, no. 3, Article ID 56C57, 2001.

[31] D. T. Patterson, "Effects of allelopathic chemicals on growth and physiological responses of soybean (Glycine max)," Weed Science, vol. 29, no. 1, pp. 53-59, 1981.

[32] D. R. Batish, H. P. Singh, N. Rana, and R. K. Kohli, "Assessment of allelopathic interference of Chenopodium albumthrough its leachates, debris extracts, rhizosphere and amended soil," Archives of Agronomy and Soil Science, vol. 52, no. 6, pp. 705-715, 2006.

[33] H. P. Singh, D. R. Batish, J. K. Pandher, and R. K. Kohli, "Assessment of allelopathic properties of Parthenium hysterophorus residues," Agriculture, Ecosystems \& Environment, vol. 95, no. 2, pp. 537-541, 2003.

[34] B. S. Ismail and T.-V. Chong, "Effects of aqueous extracts and decomposition of Mikania micrantha H.B.K. debris on selected agronomic crops," Weed Biology and Management, vol. 2, no. 1, pp. 31-38, 2002. 